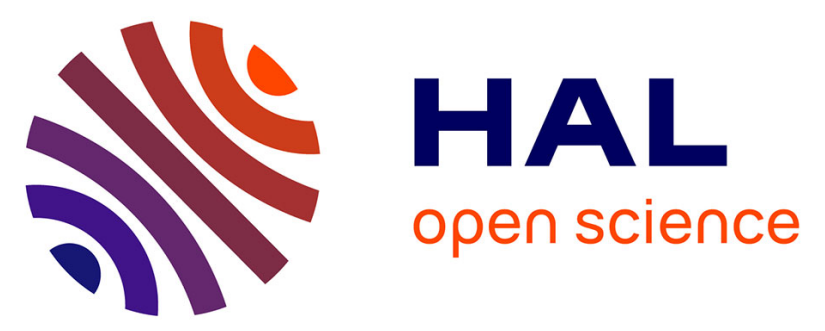

\title{
Walnut-Enriched Diet Elevated $\alpha$-Linolenic Acid, Phytoprostanes, and Phytofurans in Rat Liver and Heart Tissues and Modulated Anti-inflammatory Lipid Mediators in the Liver
}

Kin Sum Leung, Jean-Marie Galano, Yu Fung Yau, Camille Oger, Thierry

Durand, Jetty Chung-Yung Lee

\section{To cite this version:}

Kin Sum Leung, Jean-Marie Galano, Yu Fung Yau, Camille Oger, Thierry Durand, et al.. WalnutEnriched Diet Elevated $\alpha$-Linolenic Acid, Phytoprostanes, and Phytofurans in Rat Liver and Heart Tissues and Modulated Anti-inflammatory Lipid Mediators in the Liver. Journal of Agricultural and Food Chemistry, In press, 10.1021/acs.jafc.0c06690 . hal-03115274

\author{
HAL Id: hal-03115274 \\ https://hal.science/hal-03115274
}

Submitted on 19 Jan 2021

HAL is a multi-disciplinary open access archive for the deposit and dissemination of scientific research documents, whether they are published or not. The documents may come from teaching and research institutions in France or abroad, or from public or private research centers.
L'archive ouverte pluridisciplinaire HAL, est destinée au dépôt et à la diffusion de documents scientifiques de niveau recherche, publiés ou non, émanant des établissements d'enseignement et de recherche français ou étrangers, des laboratoires publics ou privés. 


\title{
Walnut-Enriched Diet Elevated $\alpha$-Linolenic Acid, Phytoprostanes, and Phytofurans in Rat Liver and Heart Tissues and Modulated Anti- inflammatory Lipid Mediators in the Liver
}

\author{
Kin Sum Leung, Jean-Marie Galano, Yu Fung Yau, Camille Oger, Thierry Durand, \\ and Jetty Chung-Yung Lee*
}

\begin{abstract}
Linolenic acid (ALA) and its non-enzymatic oxidized products, namely, phytoprostanes and phytofurans, are found in some nuts. The uptake and deposition of these compounds are not well-defined. Walnut has high ALA and a considerable amount of phytoprostanes and phytofurans compared to other common nuts. When fed to rodents, ALA and eicosapentaenoic acid levels increased in the liver and heart tissues compared to the control diet. Furthermore, phytoprostanes and phytofurans were elevated 3fold in both tissues after a walnut diet, indicating that they are not only contributed from the diet but also generated through in vivo autoxidation of ALA found in the walnuts. It was further noted that a walnut diet reduced 5- $\mathrm{F}_{2 \mathrm{t}}$-isoprostanes and 12hydroxyeicosatetraenoic acid and induced $4-\mathrm{F}_{4 \mathrm{t}}$-neuroprostane and significant amounts of anti-inflammatory hydroxydocosahexaenoic acid in the liver only. Altogether, high ALA in a walnut diet elevated phytoprostanes and phytofurans in the liver and heart tissues and showed the regulation of anti-inflammatory lipid mediators in the liver only.
\end{abstract}

KEYWORDS: walnut, $\alpha$-linolenic acid, phytoprostanes, phytofurans, neuroprostanes

\section{INTRODUCTION}

Regular consumption of nuts alleviates cardiovascular risk factors, such as dyslipidemia, type 2 diabetes, and metabolic syndrome, and the risk of coronary heart disease (CHD). ${ }^{1-3}$ Nuts are rich in unsaturated fatty acids, protein, fibers, plant sterols, minerals, and antioxidants, including vitamins and phenolic compounds. The macronutrient profiles in most nuts are similar. However, the ratios of monounsaturated and polyunsaturated fatty acids, types and amounts of phenolic compounds, vitamins, and minerals are different in each nut; therefore, consumption of different nuts contributes to different health benefits. ${ }^{4}$

Walnuts are rich in fatty acids and contain a profound number of phytochemicals, including phenolic acids, flavonoids, lignin, tannins, etc. ${ }^{5}$ Among all tree nuts, walnuts consist of the lowest ratio of saturated fatty acids (SFAs) and the highest ratio of omega- $3(n-3)$ and omega-6 (n-6) polyunsaturated fatty acids (PUFAs) to total fatty acids. ${ }^{6}$ It is believed that walnut consumption is important for improving liver and heart health. Barrera et al. reported that continuous walnut intake for 3 months can reduce liver damage markers, including alanine transaminase (ALT), aspartate transaminase (AST) and $\gamma$-glutamyl transferase (GGT), in patients with non-alcoholic fatty liver disease, ${ }^{7}$ while Han et al. reported that low intake of nuts in the diet is associated with a significantly higher risk of non-alcoholic fatty liver disease. ${ }^{8}$ Multiple studies revealed that regular consumption of walnut $(30-100 \mathrm{~g}$ per day) reduced the risk of cardiovascular diseases ${ }^{9,10}$ as well as decreased aortic endothelin 1 and other cardiovascular disease risk factors in hamsters. ${ }^{11}$ However, studies relating to walnut and its health benefits to the liver and heart are not conclusive.

Phytoprostanes (PhytoPs) are predominantly formed through non-enzymatic oxidation of $\alpha$-linolenic acid (ALA). Insofar, researchers have successfully characterized different kinds of PhytoPs in plant foods, including gulupa shells, ${ }^{12}$ leaves, ${ }^{13}$ some common nuts, ${ }^{14}$ and oil samples, ${ }^{15}$ which were further shown to be reliable in vivo oxidative stress biomarkers for plants. Recently, Minghetti et al. reported PhytoPs to be bioactive in mammalian cells. The group showed that $\mathrm{B}_{1^{-}}$ PhytoP enhanced metabolic activity and prevented human neuroblastoma (SH-SY5Y) cell death when induced with oxidative stress using $\mathrm{H}_{2} \mathrm{O}_{2}$. They also observed that $16-\mathrm{B}_{1}$ PhytoP protected SH-SY5Y cells against oxidative injury by activating PPAR- $\gamma$, a ligand-dependent transcription factor that regulates several antioxidant enzymes. ${ }^{16}$ Recently, it was also discovered that glycerol-bound PhytoPs can contribute to allergic inflammation. ${ }^{17}$

During the non-enzymatic oxidation process, when exposed to high oxygen tension, the release of phytofurans (PhytoFs) becomes predominant. We recently had access to PhytoFs thanks to our total synthesis work. ${ }^{18,19}$ Regardless, the biological role of PhytoFs is not well-understood. To date, 
PhytoPs and PhytoFs were characterized in some common nut and seed samples ${ }^{18}$ and leaves of a melon plant. ${ }^{13}$

There is a lack of information in the development of PhytoPs and PhytoFs in vivo when food rich in ALA is consumed. Furthermore, it is unknown if ALA autoxidizes in vivo to produce PhytoPs and PhytoFs for a functional role or absorbed from food resources. In this study, we measured ALA, PhytoPs, and PhytoFs in some common nuts (almond, peanut, pine nut, and walnut) found in the Asian diet. Among the nuts, walnut had a rich content of ALA and the highest amount of total PhytoPs (9- $\mathrm{D}_{1 \mathrm{t}}-\mathrm{PhytoP}, 9-\mathrm{F}_{1 \mathrm{t}}-\mathrm{PhytoP}, 16-\mathrm{F}_{1 \mathrm{t}^{-}}$ PhytoP, 9- $\mathrm{L}_{1}$-PhytoP, and 16- $\mathrm{B}_{1}$-PhytoP) and PhytoF [16(RS)-13-epi-ST- $\left.\Delta^{14}-9-\mathrm{PhytoF}\right]$. To further understand the uptake and absorption, a walnut diet was fed to Sprague Dawley (SD) rats and then profiled for n-6 and n-3 PUFAs and related lipid mediators in the liver and heart tissues using targeted lipidomics. Here, we report for the first time that ALA in walnut increased n-3 PUFA levels as well as its PhytoP and PhytoF metabolites in the liver and heart tissues. Our observation suggests that ALA from walnut contributed to the development of PhytoPs and PhytoFs in vivo and was not influenced by the content in walnut. Furthermore, rich ALA elevated anti-inflammatory lipid mediators and reduced inflammatory lipid mediators, suggesting its health benefits in the human diet.

\section{MATERIALS AND METHODS}

Materials. All solvents used in the experiments were highperformance liquid chromatography (HPLC)-grade. PUFA and oxidized lipid product standards and heavy labeled internal standards were purchased from Cayman Chemical Co. (Ann Arbor, MI, U.S.A.) or synthesized by the Institute des Biomolécules Max Mousseron (IBMM, Montpellier, France).

Animal Experiment. Eight-week-old male Sprague Dawley rats ( $n$ = 16) were obtained from Charles River Laboratories International, Wilmington, MA, U.S.A., and bred in the Animal House, School of Biological Sciences, The University of Hong Kong (HKU). The rats were randomly assigned into two groups, control and walnut, with 8 rats in each group. The control group was fed with Open Standard Diet D11112221 (Research Diets, New Brunswick, NJ, U.S.A.), and the walnut group were fed with a walnut-enriched diet $(9.5 \%$ ground walnut, w/w). All diets were isocaloric ( $18 \% \mathrm{kcal}$ of protein, $65 \% \mathrm{kcal}$ of carbohydrate, and $16 \% \mathrm{kcal}$ of fat) made by Research Diets, and the composition details are shown in Table S1 of the Supporting Information.

The use of live animals and the protocols of the animal studies were approved by the Department of Health of the Hong Kong Special Administrative Region of the People's Republic of China (HKSAR) Government and the committee of the Use of Live Animal in Teaching and Research of HKU (CULATR 3733-15). The rats were separated into groups of two in a solid-bottom polycarbonate cage with autoclaved hardwood bedding, with free access to deionized, reverse-osmosis-treated water and sterile rodent diets ad libitum. The animals experienced $12 \mathrm{~h}$ light and dark cycles in a room set to 20-25 ${ }^{\circ} \mathrm{C}$ with $35-70 \%$ relative humidity. The body weight, feed intake, and signs of abnormality were monitored throughout the study. The animal experiments commenced after 1 week of acclimatization and were complied with the local institutional ethical guidelines. After 28 days of feeding, the animals were sacrificed via cervical dislocation. Liver and heart tissues were immediately harvested, washed with phosphate-buffered saline (PBS) containing $0.005 \%(\mathrm{w} / \mathrm{v})$ butylated hydroxytoluene (BHT) and $0.005 \%(\mathrm{w} / \mathrm{v})$ indomethacin, and stored at $-80{ }^{\circ} \mathrm{C}$.

Lipid Extraction in Nuts and Animal Tissues. Four different kinds of common nuts, including almond (organic, U.S.A.), peanut (organic, China), pine nut (organic, Italy), and walnut (organic, shelled, Italy), were purchased from a local food market. These nuts were raw and organic, without any heat treatments or the addition of seasonings and food additives. The samples were finely ground by an electronic grinder (Kenwood AT320A), and PUFAs and oxidized lipid products were extracted by Folch extraction and purified by solid-phase extraction (SPE) according to previous studies, with modifications. ${ }^{20,21}$ In brief, $0.05 \mathrm{~g}$ of ground nuts or animal tissues (liver and heart) were homogenized in $5 \mathrm{~mL}$ of cold Folch solution (chloroform/methanol, 2:1, v/v) with $0.01 \%$ BHT (w/v) at 24000 $\mathrm{rpm}$ in $20 \mathrm{~s}$ bursts on ice using a polytron benchtop homogenizer (T25, Ultra-Turrax, IKA, Germany). After the homogenization, phase separation was induced by $2 \mathrm{~mL}$ of $0.9 \%$ aqueous sodium chloride. It was then centrifuged at $4{ }^{\circ} \mathrm{C}$ and $3000 \mathrm{~g}$ for $10 \mathrm{~min}$, and the lower organic phase was collected in a glass vial. The extracts were dried completely under a stream of nitrogen, and hydrolysis was performed using $1 \mathrm{~mL}$ of $1 \mathrm{M}$ methanolic potassium hydroxide with $0.01 \% \mathrm{BHT}$, $1 \mathrm{~mL}$ of PBS (pH 7.4), and $100 \mu \mathrm{L}$ of internal standard mix (Table S2 of the Supporting Information) in the dark overnight. The alkaline hydrolysis was terminated by adding $200 \mu \mathrm{L}$ of $5 \mathrm{~N}$ hydrochloric acid, $0.5 \mathrm{~mL}$ of methanol, $2.7 \mathrm{~mL}$ of $40 \mathrm{mM}$ aqueous formic acid, and $4 \mathrm{~mL}$ of $20 \mathrm{mM}$ aqueous formic acid. The hydrolyzed samples were then purified by SPE using $60 \mathrm{mg}$ MAX columns (Oasis, Waters, Milford, MA, U.S.A.). The purified samples were dried under a stream of nitrogen gas and resuspended afterward with $100 \mu \mathrm{L}$ of acetonitrile. The final extracts were aliquoted into autosampler vials with an insert and were immediately analyzed using liquid chromatography-tandem mass spectrometry (LC-MS/MS).

Quantification of PUFAs and Oxidized Lipid Products by LC-MS/MS. PUFAs and oxidized lipid products were analyzed according to previous studies, with modifications. ${ }^{21-23}$ Briefly, LCMS/MS analysis was performed using a 1290 Infinity LC system (Agilent Technologies, Santa Clara, CA, U.S.A.) with a Kinetex C18 column $(150 \times 21 \mathrm{~mm}, 2.6 \mu \mathrm{m}$, Phenomenex, Torrance, CA, U.S.A.). Milli-Q water/formic acid (99.9:0.1, v/v) and acetonitrile/formic acid (99.9:0.1, v/v) were used as solvents A and B, respectively, for the mobile phases in the LC system. The flow rate was $0.3 \mu \mathrm{L} / \mathrm{min}$, and a stepwise gradient elution was set as follows: first, $20 \%$ B was kept for the first $2 \mathrm{~min}$, then a gradual elevation of B to $98 \%$ was achieved from 2 to $10 \mathrm{~min}$, and $98 \%$ B was maintained for $5 \mathrm{~min}$. Finally, the mobile phase was set back to $20 \%$ B from 15 to $15.1 \mathrm{~min}$ and kept until $20 \mathrm{~min}$ to prepare for the next run. The autosampler was operated at $4{ }^{\circ} \mathrm{C}$, and the injection volume of each sample was $10 \mu \mathrm{L}$.

The LC system coupled to a QTrap 3200 mass spectrometer (Sciex Applied Biosystems, Waltham, MA, U.S.A.) with electrospray ionization (ESI) was used. The ESI was run in negative atmospheric pressure chemical ionization (APCI) mode, and the analytes were detected by MS/MS using multiple reaction monitoring (MRM). The source temperature was set at $325^{\circ} \mathrm{C}$, the spray voltage was set to $-3000 \mathrm{~V}$ and nitrogen gas was used as curtain gas. The concentration of the sample analytes was determined by associating the peak area of the analyte with the peak area of the corresponding internal standard. The deuterated form of the analytes where available was used as internal standards for quantitation. The complete set of $\mathrm{m} / z$ for each analyte is described in Table S2 of the Supporting Information. The $m / z$ values are derived from the standards available commercially and synthesized by IBMM, and the others are from the LIPID MAPS database and literature reports. For analytes without deuterated standards, the peak area of the deuterated standards having the closest chemical structure were used as the internal standard for the quantitation of those analytes.

Reverse Transcription and Quantitative Real-Time Polymerase Chain Reaction (qPCR). Total RNA was extracted and purified from the rat heart tissue using TRIzol reagent (Invitrogen, Carlsbad, CA, U.S.A.), and the cDNA was generated from RNA using a high-capacity RNA-to-cDNA kit (Applied Biosystems, Foster City, CA, U.S.A.). The extraction procedures are according to the manual of the manufacturer. A real-time PCR reaction mixture was prepared by adding $1 \mu \mathrm{L}$ of sample cDNA $(\sim 40 \mathrm{ng} / \mu \mathrm{L}), 1 \mu \mathrm{L}$ of forward and reverse primer mix (10 $\mu \mathrm{M}$, Invitrogen, CA, U.S.A.), $3 \mu \mathrm{L}$ of diethylpyrocarbonate (DEPC) water, and $5 \mu \mathrm{L}$ of $2 \times$ SYBR green PCR master mix (Applied Biosystems, Foster City, CA, U.S.A.) to a 
96-well plate. The reaction was run by a Step-One Plus real-time thermal cycler (Applied Biosystems, Foster City, CA, U.S.A.), and the PCR conditions were as follows: first, a hot start at $95{ }^{\circ} \mathrm{C}$ for $15 \mathrm{~min}$, then denaturation with 40 cycles of $95{ }^{\circ} \mathrm{C}$ for $15 \mathrm{~s}$, and finally annealing at $60^{\circ} \mathrm{C}$ for $1 \mathrm{~min}$. All of the samples were run in triplicate, and the experiments were repeated thrice for data confirmation. The results obtained were calculated using the $\Delta \Delta C_{\mathrm{q}}$ method and recorded as fold change. The primers used in this study (Table S3 of the Supporting Information) were in-house-designed and validated using 2\% agarose gel electrophoresis. A single band represents that the primers have a high specificity, while two or more bands observed in the gel indicated that the primers need to be redesigned.

Statistical Analysis. All data were analyzed by GraphPad Prism (version 7 for PC, GraphPad Software, Inc., La Jolla, CA, U.S.A.) and reported as the mean \pm standard deviation $(\mathrm{SD})$. Data were analyzed by an unpaired, non-parametric $t$ test (Mann-Whitney test, two tailed). A $p$ value of $<0.05$ was denoted as statistically significant.

\section{RESULTS}

ALA, PhytoP, and PhytoF Contents of the Nut Samples. The concentrations of ALA and its oxidized lipid products PhytoPs and PhytoFs were quantified in four different common nuts purchased in local food markets (Figures 1 and 2). Among the samples, walnut had the highest amount of ALA as well as total PhytoPs (Figure 1).

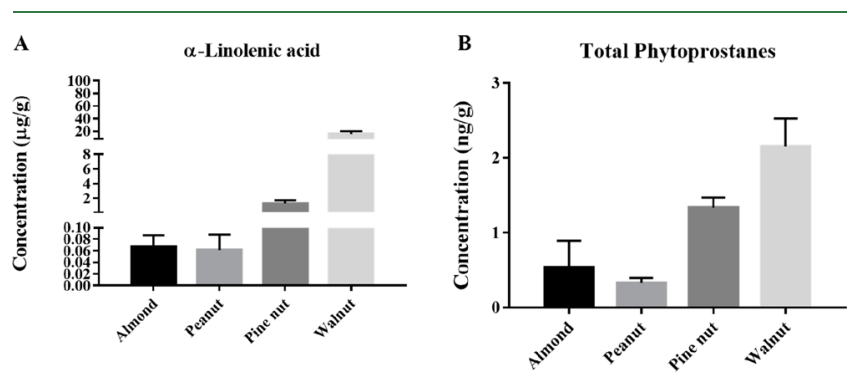

Figure 1. Concentrations of ALA and total PhytoPs measured in common nuts. Data are presented as the mean \pm SD $(n=4)$. The concentration is shown as micrograms per gram of nut samples for (A) ALA and nanograms per gram of nut samples for (B) total PhytoPs in nut samples.

Not all types of the PhytoPs were detectable in the nut samples (Figure 2). Only 9- $\mathrm{F}_{1 \mathrm{t}}$-PhytoP, 9- $\mathrm{L}_{1}-\mathrm{PhytoP}$, and 16(RS)-13-epi-ST- $\Delta^{14}-9$-PhytoF were measurable in the nut samples, where the highest concentration was $9-\mathrm{F}_{1 \mathrm{t}}$ PhytoP. Notably, 16- $\mathrm{F}_{1 \mathrm{t}}-\mathrm{PhytoP}$ was only found in walnut. Altogether, walnut was the only sample that contained all types of PhytoPs and one PhytoF and the highest concentration of PhytoPs among the four nut samples. Therefore, it was selected for further investigation on the uptake in the liver and heart tissues.

Walnut Diet Did Not Affect Rat Weight Gain and Food Intake. The physical characteristics of the rats during the feeding period showed that the flavor and smell of the walnut enriched in the diet did not affect the appetite of the rats because there was no significant difference in chow consumption for both groups. In addition, since the diets were formulated to be isocaloric, the body weight gain of the rats between control and walnut groups also did not show a significant difference (Figure S1 of the Supporting Information). The average daily walnut diet consumption was $29.48 \mathrm{~g}$; thus, the rats consumed $2.80 \mathrm{~g}$ of walnut per day containing approximately $0.27 \mathrm{~g}$ of ALA. For the control diet, soybean oil was the main fat contributor in the diet. The average daily
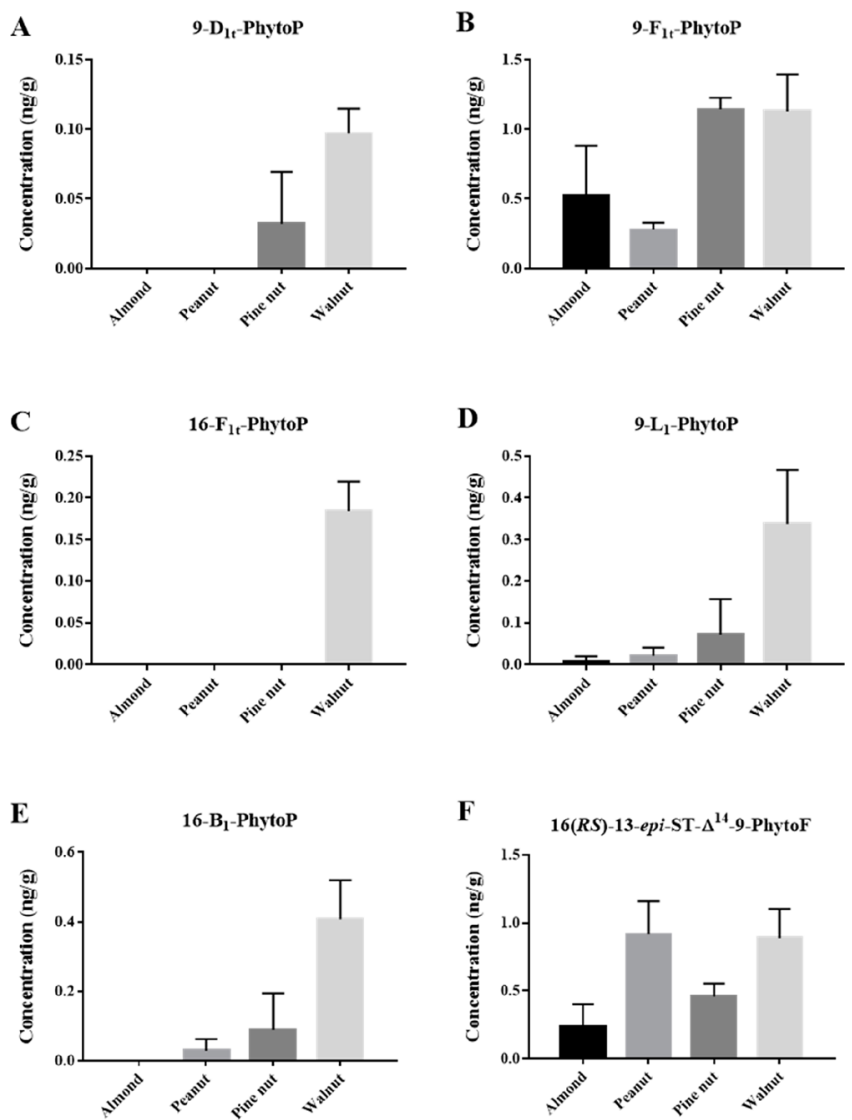

Figure 2. Concentrations of PhytoPs and PhytoF measured in common nuts. Data are presented as the mean \pm SD $(n=4)$. The concentration is shown as nanograms per gram of nut samples.

control diet consumption was $26.99 \mathrm{~g}$ thus, $1.78 \mathrm{~g}$ of soybean oil per day was taken, which contained approximately $0.07 \mathrm{~g}$ of ALA. Therefore, the walnut diet contained almost 4 times higher ALA than the control diet.

n-3 PUFAs and Their Oxidized PUFAs Were Upregulated, while Those of $n-6$ PUFAs Were Downregulated by the Walnut Diet in the Liver Tissue. PUFAs and their oxidized products were measured in the rat liver to evaluate if the walnut-enriched diet altered the lipid metabolism. It was found that the walnut diet reduced n- 6 PUFA levels, including arachidonic acid (AA) and adrenic acid (AdA), while elevated n-3 PUFA levels, including ALA, eicosapentaenoic acid (EPA), and $n-3$ docosapentaenoic acid (n-3 DPA), compared to the control. However, the docosahexaenoic acid (DHA) level was not modified by the walnut diet (Figure 3).

Similar to PUFAs, the walnut diet significantly downregulated n-6 PUFA-related enzymatic oxidized products, in particular 12-HETE, while it significantly upregulated $n-3$ PUFA-related enzymatic oxidized products, including 7-, 11-, and 17-HDHA, compared to the control. Levels of 5-, 8-, and 15-HETE and 4- and 14-HDHA were not modified by the walnut diet. Moreover, the total lipoxygenase (LOX)-mediated hydroxyeicosatetraenoic acid (HETE) level was significantly lower than total LOX-mediated hydroxydocosahexaenoic acids (HDHAs) after walnut diet consumption compared to the control (Table 1).

For non-enzymatic oxidized products of PUFAs, only the 5$\mathrm{F}_{2 \mathrm{t}}$-IsoP level derived from AA in the liver was significantly lowered by the walnut diet. There was no change for $5-\mathrm{F}_{3 \mathrm{t}}-\mathrm{IsoP}$ 
A
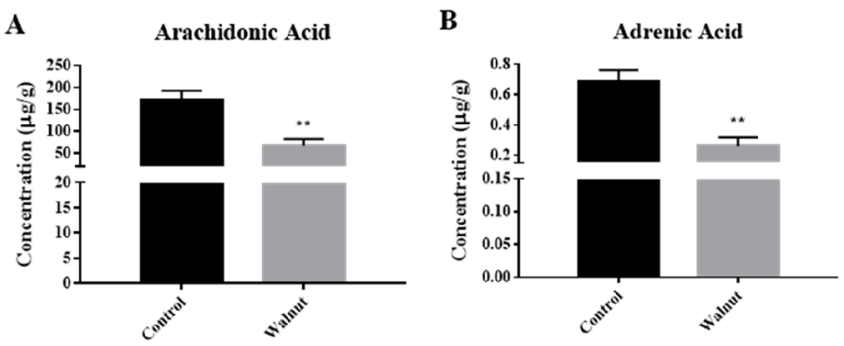

C

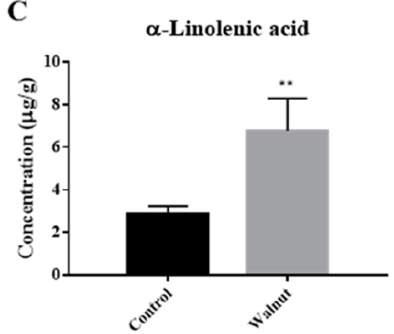

$\mathbf{E}$

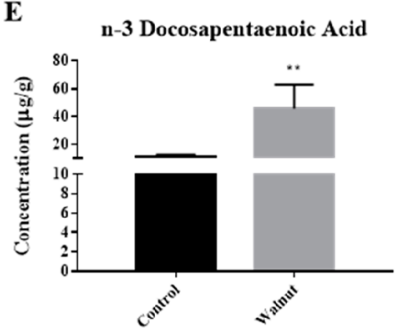

D

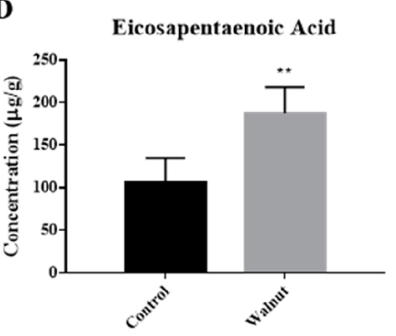

$\mathbf{F}$

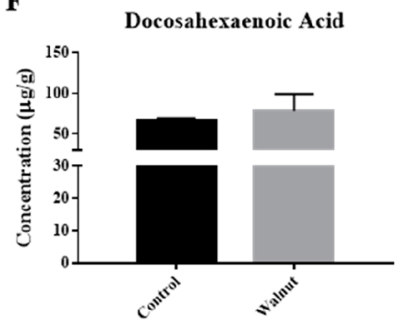

Figure 3. Levels of PUFAs measured in the liver tissue. Graphs represent (A) arachidonic acid, (B) adrenic acid, (C) $\alpha$-linolenic acid, (D) eicosapentaenoic acid, (E) n-3 docosapentaenoic acid, and (F) docosahexaenoic acid measured in the rat liver tissue. The concentration is shown as micrograms per gram of tissue samples. Data are presented as the mean $\pm \mathrm{SD}(n=8)$. (**) $p<0.01$ compared to the control.

Table 1. Levels of Enzymatic Oxidized PUFA Products Measured in the Liver Tissue ${ }^{a}$

\begin{tabular}{|c|c|c|}
\hline & control & walnut \\
\hline \multicolumn{3}{|c|}{ Enzymatic Oxidized Products from AA } \\
\hline 5-HETE & $0.11 \pm 0.06$ & $0.07 \pm 0.01$ \\
\hline 8-HETE & $0.96 \pm 0.17$ & $0.79 \pm 0.18$ \\
\hline 12-HETE & $2.17 \pm 0.18$ & $1.64 \pm 0.27^{b}$ \\
\hline 15-HETE & $0.09 \pm 0.02$ & $0.08 \pm 0.02$ \\
\hline total LOX-mediated HETEs & $3.36 \pm 0.21$ & $2.57 \pm 0.46^{c}$ \\
\hline \multicolumn{3}{|c|}{ Enzymatic Oxidized Products from DHA } \\
\hline 4-HDHA & $3.25 \pm 1.51$ & $3.21 \pm 0.73$ \\
\hline 7-HDHA & $0.04 \pm 0.02$ & $0.11 \pm 0.04^{b}$ \\
\hline 11-HDHA & $17.63 \pm 8.62$ & $39.69 \pm 17.84^{c}$ \\
\hline 14-HDHA & $6.89 \pm 1.95$ & $15.78 \pm 10.57$ \\
\hline 17-HDHA & $45.20 \pm 22.68$ & $105.07 \pm 29.42^{c}$ \\
\hline total LOX-mediated HDHAs & $73.02 \pm 20.21$ & $163.87 \pm 51.07^{b}$ \\
\hline
\end{tabular}

${ }^{a}$ Data are presented as the mean \pm SD $(n=8)$. HETE, hydroxyeicosatetraenoic acid; HDHA, hydroxydocosahexaenoic acid; LOX, lipoxygenase; total LOX-mediated HETEs, sum of 5-, 8-, 12-, and 15-HETE; and total LOX-mediated HDHAs, sum of 4-, 7-, 11-, 14-, and 17-HDHA. The concentration is shown as nanograms per gram of tissue samples. ${ }^{b} p<0.01$ compared to the control. ${ }^{c} p<0.05$ compared to the control.

and $15-\mathrm{F}_{3 \mathrm{t}}$-IsoP levels derived from EPA in the liver by the walnut diet compared to the control (Table 2). Those from

Table 2. Levels of Non-enzymatic Oxidized PUFA Products Measured in the Liver Tissue ${ }^{a}$

\begin{tabular}{|c|c|c|}
\hline & control & walnut \\
\hline \multicolumn{3}{|c|}{ Non-enzymatic Oxidized Products from AA } \\
\hline $5-\mathrm{F}_{2 \mathrm{t}}$-IsoP & $3.88 \pm 1.49$ & $0.86 \pm 0.37^{b}$ \\
\hline $15-\mathrm{F}_{2 \mathrm{t}}$-IsoP & $12.85 \pm 1.88$ & $11.56 \pm 1.30$ \\
\hline \multicolumn{3}{|c|}{ Non-enzymatic Oxidized Products from ALA } \\
\hline 9- $\mathrm{D}_{1 \mathrm{t}}$-PhytoP & $13.17 \pm 6.91$ & $57.26 \pm 18.10^{b}$ \\
\hline 9- $\mathrm{F}_{1 \mathrm{t}}$-PhytoP & $8.14 \pm 3.32$ & $31.28 \pm 2.80^{b}$ \\
\hline 16- $\mathrm{F}_{1 \mathrm{t}}-\mathrm{PhytoP}$ & $3.70 \pm 1.97$ & $21.55 \pm 5.37^{b}$ \\
\hline 9- $\mathrm{L}_{1}$-PhytoP & $4.54 \pm 2.89$ & $17.25 \pm 2.65^{b}$ \\
\hline 16-B B $_{1}$-PhytoP & $1.56 \pm 1.71$ & $26.05 \pm 9.36^{b}$ \\
\hline $16(R S)-13-S T-\Delta^{14}-9-P h y t o F$ & $0.72 \pm 0.19$ & $7.40 \pm 0.35^{b}$ \\
\hline \multicolumn{3}{|c|}{ Non-enzymatic Oxidized Products from EPA } \\
\hline $5-\mathrm{F}_{3 \mathrm{t}}-\mathrm{IsoP}$ & $3.43 \pm 0.87$ & $2.67 \pm 1.69$ \\
\hline $15-\mathrm{F}_{3 \mathrm{t}}$-IsoP & $1.51 \pm 1.11$ & $1.82 \pm 1.15$ \\
\hline \multicolumn{3}{|c|}{ Non-enzymatic Oxidized Products from DHA } \\
\hline $4-\mathrm{F}_{4 \mathrm{t}}-\mathrm{NeuroP}$ & $5.49 \pm 0.92$ & $10.07 \pm 3.84^{c}$ \\
\hline $10-\mathrm{F}_{4 \mathrm{t}}-$ NeuroP & $8.88 \pm 1.11$ & $11.98 \pm 2.50$ \\
\hline 8-HDHA & $6.12 \pm 2.44$ & $6.24 \pm 1.73$ \\
\hline 10-HDHA & $0.25 \pm 0.09$ & $0.54 \pm 0.22^{c}$ \\
\hline 13-HDHA & $0.46 \pm 0.13$ & $1.13 \pm 0.32^{b}$ \\
\hline 16-HDHA & $0.84 \pm 0.24$ & $4.83 \pm 1.29^{d}$ \\
\hline
\end{tabular}

${ }^{a}$ Data are presented as the mean \pm SD $(n=8)$. HDHA, hydroxydocosahexaenoic acid; IsoP, isoprostane; and NeuroP, neuroprostane. The concentration is shown as nanograms per gram of tissue samples. ${ }^{b} p<0.01$ compared to the control. ${ }^{c} p<0.05$ compared to the control. ${ }^{d} p<0.001$ compared to the control.

DHA, including 4-, 10-, and 13- $\mathrm{F}_{4 \mathrm{t}}-\mathrm{NeuroPs}$ and 16-HDHA, and all PhytoPs (9-D $\mathrm{D}_{1 \mathrm{t}}$-PhytoP, 9- $\mathrm{F}_{1 \mathrm{t}}-\mathrm{Phyto}$, 16- $\mathrm{F}_{1 \mathrm{t}}$-PhytoP, 9$\mathrm{L}_{1}$-PhytoP, and $16-\mathrm{B}_{1}-$ PhytoP) and PhytoF [16(RS)-13-epiST- $\left.\Delta^{14}-9-\mathrm{PhytoF}\right]$ derived from ALA were significantly elevated by the walnut diet compared to the control (Table 2 ). Levels of $10-\mathrm{F}_{4 \mathrm{t}}-\mathrm{NeuroP}$ and $8-\mathrm{HDHA}$ were not modified by the walnut diet.

Walnut Diet Mainly Altered PUFAs, PhytoPs, and PhytoFs in the Heart Tissue. The walnut diet significantly upregulated ALA, EPA, and $\mathrm{DPA}_{\mathrm{n}-3}$ levels but not DHA, while it downregulated AA and AdA in the heart tissue compared to the control (Figure 4). For enzymatic oxidized products, only the 15-HETE level was found to be reduced and the 4-HDHA level was found to be elevated by the walnut diet compared to the control. Other enzymatic oxidized products (5-, 8-, and 12HETE and 7-, 11-, 14-, and 17-HDHA) did not change in the heart tissue after the walnut diet compared to the control (Table 3).

For non-enzymatic oxidized products, all PhytoPs $\left(9-\mathrm{D}_{1 \mathrm{t}^{-}}\right.$ PhytoP, 9- $\mathrm{F}_{1 \mathrm{t}}-$ PhytoP, 16- $\mathrm{F}_{1 \mathrm{t}}-\mathrm{Phyto}$, 9- $\mathrm{L}_{1}-\mathrm{PhytoP}$, and 16$\mathrm{B}_{1}-$ PhytoP) and PhytoF $\left[16(R S)-13\right.$-epi-ST- $\left.\Delta^{14}-9-\mathrm{PhytoF}\right]$ levels, which are derived from ALA, showed significant elevation after the walnut diet (Table 4). Levels of nonenzymatic oxidized products derived from AA (5- $\mathrm{F}_{2 \mathrm{t}} \mathrm{-}$ - soP and 15- $\mathrm{F}_{2 \mathrm{t}}$-IsoP), EPA (5- $\mathrm{F}_{3 \mathrm{t}}$-IsoP and $15-\mathrm{F}_{3 \mathrm{t}}$-IsoP), and DHA (4$\mathrm{F}_{4 \mathrm{t}^{-}}$and 10- $\mathrm{F}_{4 \mathrm{t}^{-}}-\mathrm{NeuroP}$ and 8-, 10-, 13-, and 16-HDHA) did not have any remarkable changes by the walnut diet compared to the control (Table 4).

No Significant Changes Were Observed in Gene Expression Related to Inflammation and Antioxidant 
A

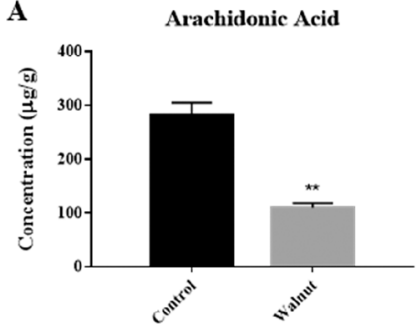

C

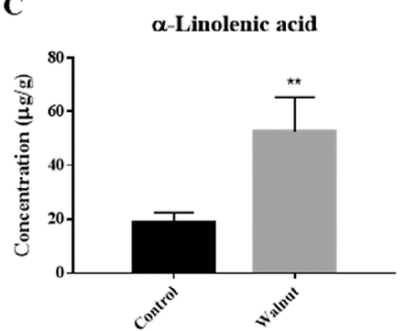

$\mathbf{E}$

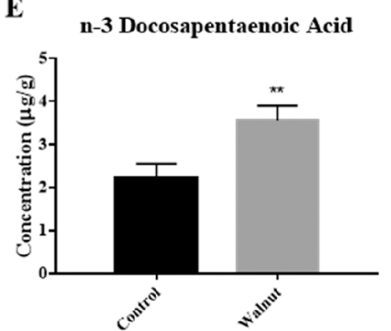

B

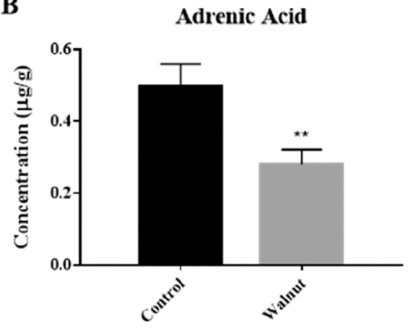

D

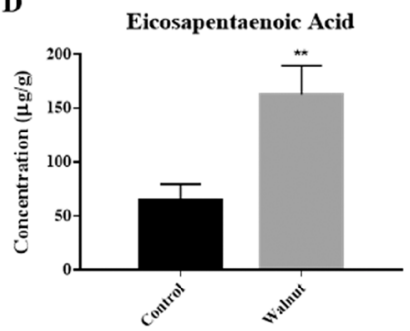

$\mathbf{F}$

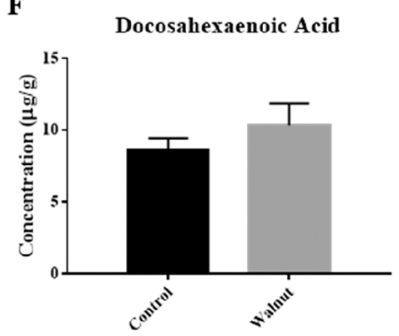

Figure 4. Levels of PUFAs measured in the heart tissue. Graphs represent (A) arachidonic acid, (B) adrenic acid, (C) $\alpha$-linolenic acid, (D) eicosapentaenoic acid, (E) n-3-type docosapentaenoic acid, and (F) docosahexaenoic acid measured in the rat heart tissue. Data are presented as the mean $\pm \mathrm{SD}(n=8)$. The concentration is shown as micrograms per gram of tissue samples. $(* *) p<0.01$ compared to the control.

Table 3. Levels of Enzymatic Oxidized PUFA Products Measured in the Heart Tissue ${ }^{a}$

\begin{tabular}{|c|c|c|}
\hline & control & walnut \\
\hline \multicolumn{3}{|c|}{ Enzymatic Oxidized Products from AA } \\
\hline 5-HETE & $0.48 \pm 0.12$ & $0.36 \pm 0.07$ \\
\hline 8-HETE & $1.09 \pm 0.25$ & $0.77 \pm 0.09$ \\
\hline 12-HETE & $4.87 \pm 1.27$ & $6.10 \pm 1.87$ \\
\hline 15-HETE & $0.53 \pm 0.08$ & $0.25 \pm 0.10^{b}$ \\
\hline total LOX-mediated HETEs & $6.97 \pm 1.52$ & $7.47 \pm 1.93$ \\
\hline \multicolumn{3}{|c|}{ Enzymatic Oxidized Products from DHA } \\
\hline 4-HDHA & $0.08 \pm 0.05$ & $0.20 \pm 0.07^{b}$ \\
\hline 7-HDHA & $0.36 \pm 0.14$ & $0.58 \pm 0.12$ \\
\hline 11-HDHA & $1.38 \pm 0.89$ & $1.82 \pm 0.05$ \\
\hline 14-HDHA & $0.45 \pm 0.07$ & $0.60 \pm 0.27$ \\
\hline 17-HDHA & $6.39 \pm 0.79$ & $8.29 \pm 3.47$ \\
\hline total LOX-mediated HDHAs & $8.66 \pm 1.52$ & $11.49 \pm 3.77$ \\
\hline \multicolumn{3}{|c|}{$\begin{array}{l}{ }^{a} \text { Data are presented as the mean } \pm \text { SD }(n=8) \text {. HETE, } \\
\text { hydroxyeicosatetraenoic acid; HDHA, hydroxydocosahexaenoic acid; } \\
\text { LOX, lipoxygenase; total LOX-mediated HETEs, sum of 5-, 8-, 12-, } \\
\text { and 15-HETE; and total LOX-mediated HDHAs, sum of 4-, 7-, 11-, } \\
\text { 14-, and 17-HDHA. The concentration is shown as nanograms per } \\
\text { gram of tissue samples. }{ }^{b} p<0.01 \text { compared to the control. }\end{array}$} \\
\hline
\end{tabular}

Enzyme after Walnut Supplementation. The measurement of the oxidized PUFA products indicates that anti-
Table 4. Levels of Non-enzymatic Oxidized PUFA Products Measured in the Heart Tissue ${ }^{a}$

\begin{tabular}{|c|c|c|}
\hline & control & walnut \\
\hline \multicolumn{3}{|c|}{ Non-enzymatic Oxidized Products from AA } \\
\hline $5-\mathrm{F}_{2 \mathrm{t}}$-IsoP & $12.61 \pm 0.99$ & $11.20 \pm 6.63$ \\
\hline $15-\mathrm{F}_{2 \mathrm{t}}$-IsoP & $144.99 \pm 24.29$ & $110.67 \pm 28.78$ \\
\hline \multicolumn{3}{|c|}{ Non-enzymatic Oxidized Products from ALA } \\
\hline 9- $\mathrm{D}_{1 \mathrm{t}}$-PhytoP & $1.69 \pm 0.86$ & $3.62 \pm 1.03^{b}$ \\
\hline 9- $\mathrm{F}_{1 \mathrm{t}}-\mathrm{PhytoP}$ & $0.30 \pm 0.11$ & $1.74 \pm 0.56^{b}$ \\
\hline $16-\mathrm{F}_{1 \mathrm{t}}-$ PhytoP & $0.77 \pm 0.39$ & $11.91 \pm 1.20^{b}$ \\
\hline 9- $\mathrm{L}_{1}$-PhytoP & $0.53 \pm 0.22$ & $2.11 \pm 0.93^{b}$ \\
\hline 16-B-B - PhytoP & $1.14 \pm 0.56$ & $18.21 \pm 5.04^{b}$ \\
\hline 16(RS)-13-ST- $\Delta^{14}-9-\mathrm{PhytoF}$ & $0.74 \pm 0.42$ & $3.57 \pm 0.94^{b}$ \\
\hline \multicolumn{3}{|c|}{ Non-enzymatic Oxidized Products from EPA } \\
\hline $5-\mathrm{F}_{3 \mathrm{t}}$-IsoP & $5.94 \pm 2.00$ & $8.03 \pm 0.98$ \\
\hline $15-\mathrm{F}_{3 \mathrm{t}}$-IsoP & $0.65 \pm 0.34$ & $0.72 \pm 0.37$ \\
\hline \multicolumn{3}{|c|}{ Non-enzymatic Oxidized Products from DHA } \\
\hline $4-\mathrm{F}_{4 \mathrm{t}}-\mathrm{NeuroP}$ & $10.15 \pm 2.56$ & $12.00 \pm 3.50$ \\
\hline $10-\mathrm{F}_{4 \mathrm{t}}-\mathrm{NeuroP}$ & $13.83 \pm 5.18$ & $11.63 \pm 3.86$ \\
\hline 8-HDHA & $0.83 \pm 0.13$ & $1.13 \pm 0.28$ \\
\hline 10-HDHA & $0.08 \pm 0.04$ & $0.09 \pm 0.02$ \\
\hline 13-HDHA & $0.14 \pm 0.08$ & $0.24 \pm 0.03$ \\
\hline 16-HDHA & $2.71 \pm 0.53$ & $3.65 \pm 0.93$ \\
\hline Data are presented a & 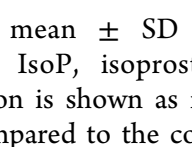 & $\begin{array}{l}\text { 8). } \mathrm{HDF} \\
\text { and Neur }\end{array}$ \\
\hline
\end{tabular}

inflammatory (HDHA) and pro-inflammatory (HETE) lipid mediators were up- and downregulated, respectively, by the walnut diet. Further evaluation of gene expressions related to inflammation, including interleukin (IL)-6, IL-1 $\beta$, and tumor necrosis factor $\alpha$ (TNF- $\alpha)$, and gene expression related to antioxidant enzyme catalase were elucidated using RT-PCR (Figure S3 of the Supporting Information). Surprisingly, none of the gene expressions was affected by the walnut diet compared to the control.

\section{DISCUSSION}

Long-chain n-3 PUFAs, including ALA, EPA, and DHA, are important to our health as they are essential fatty acids and also, protect against chronic diseases, such as CVD, neurodegenerative disease, and inflammatory-related diseases. ${ }^{24-27}$ Consumption of dietary n-3 PUFAs is necessary since ALA cannot be synthesized in the human body due to the absence of $\Delta^{12}$ and $\Delta^{15}$ desaturase enzymes. ${ }^{28}$ ALA can be obtained from plant-based food, such as plant oils, nuts, and seeds. However, it is known that the skipped diene bonds in the structure of ALA readily oxidize non-enzymatically to release PhytoPs and PhytoFs. ${ }^{18,29}$ Nonetheless, it is unclear if PhytoPs and PhytoFs found in vivo are contributed by the diet or attributed by the autoxidation of ALA.

Presently, a handful of literature could be found related to PhytoPs, and the majority of the studies focused on oxidative stress and higher plants. ${ }^{12,14,15}$ Reports on PhytoFs are even less because they were only recently synthesized and discovered by Cuyamendous et al. ${ }^{13,18,19}$ In this study, the levels of ALA, PhytoPs, and one PhytoF were measured in edible nuts, including almond, peanut, pine nut, and walnut. A high level of ALA ( $>10 \mu \mathrm{g} / \mathrm{g})$ was found in walnut; a medium level of ALA $(1-10 \mu \mathrm{g} / \mathrm{g})$ was found in pine nut, and a low level of ALA $(<0.1 \mu \mathrm{g} / \mathrm{g})$ was found in almond and peanut. In 
general, we observed that nuts with a high level of ALA contained more PhytoPs. Walnut had the highest level of ALA and also all types of PhytoPs, whereas for PhytoF, all nuts contain similar levels. This is probably because the formation of PhytoFs requires high oxygen tension, which normally will not exist in common packaging or storage conditions of these nuts. ${ }^{19}$ More so, it is likely that these nuts were not under oxidative stress during growth.

To elucidate the etiology of PhytoPs and PhytoF, walnut was chosen for the diet in the in vivo study because it had the highest ALA, PhytoP, and PhytoF levels among the nut samples tested. Both the liver and heart tissues were found to have high levels of n-3 PUFAs, except DHA, and lower levels of $n-6$ PUFAs compared to the control. The changes in the PUFA profile in both tissues were probably due to concentrated ALA in walnut. When absorbed, it is likely that ALA and linoleic acid (LA) competed in the metabolism for the same set of desaturating and elongating enzymes for the formation of EPA and DHA and AA, respectively. Studies showed that altering the ratio of ALA/LA in the diet can regulate the levels of n-3 and n-6 PUFAs in animal tissues. ${ }^{30,31}$ Consequently, as shown in our study, increasing ALA in the diet can upregulate the levels of ALA, n-3 DPA, and EPA in the tissues. Despite this, the walnut diet did not upregulate DHA in the tissues. In fact, several studies had same findings. Gibson et al. even reported that the DHA levels in plasma negatively correlated with the level of ALA in the diet. ${ }^{32}$ It is suggested that ALA can inhibit the formation of DHA by competing with the same enzyme for the conversion, i.e., $\Delta^{6}$ desaturase, ${ }^{33}$ which is the reason why a high level of ALA in the diet can suppress DHA formation and accumulation in the tissues.

Increasing the levels of ALA in the diet also modified the oxidized PUFA products in the tissues. From our findings, it indicated that LOX-mediated HETEs generated from AA were reduced, while LOX-mediated HDHA generated from DHA increased. The reduction in pro-inflammatory LOX-mediated oxidized products from AA and the elevation in antiinflammatory LOX-mediated oxidized products from DHA may be due to the downregulation of $\mathrm{AA}$ in the liver after consuming a walnut diet.

Both Jump et al. and Endo et al. suggested that in vivo elevation of n-3 PUFAs, in particular EPA and DHA, through the diet will increase the assimilation of $n-3$ PUFAs into the sn2 position of membrane phospholipids. ${ }^{34,35}$ Because cellular phospholipase A2 will release the PUFAs from membrane phospholipids at the sn2 position for the substrate of cyclooxygenase (COX), LOX, and cytochrome P450 (CYP450) enzymes, the elevation of n-3 PUFAs at the sn2 position of the membrane phospholipid will upregulate the generation of anti-inflammatory oxidized products from n-3 PUFAs and also downregulate the generation of proinflammatory eicosanoids from n-6 PUFAs. Several cell studies also reported that EPA was able to compete with AA to generate less pro-aggregatory thromboxane TXA3 instead of TXA2 via COX and generate less pro-inflammatory eicosanoid LTB5 instead of LTB4 via LOX. . $^{36-38}$

In addition, during the enzymatic oxidation process of AA, EPA, and DHA, they rely on the same set of enzymes, including LOX, COX, and CYP450. As a result, the reduction of AA by the walnut diet potentially increased the competition of EPA and DHA for these enzymes; therefore, it is plausible that the oxidation products of EPA and DHA are increased, even though DHA was not upregulated in the tissues.
Nonetheless, more types of eicosanoids, including prostaglandins, leukotrienes, and thromboxanes, from both n-3 and n-6 PUFAs need to be determined in the liver to have a full understanding on changes of enzymatic PUFA oxidation after increasing levels of ALA, PhytoPs, and PhytoFs from diets.

Non-enzymatic oxidized products from AA, mainly the 5$\mathrm{F}_{2 \mathrm{t}}$-IsoP level, were also reduced in the liver by the walnut diet and probably due to the reduction of $\mathrm{AA}$ and the antioxidative properties of phytochemicals in walnut. Walnuts contain high levels of numerous phytochemicals. Several literature reported that tannins, flavonoids, and phenolic acids in walnuts contribute to the antioxidative properties of walnut, which can help reduce oxidation of unsaturated fats. ${ }^{39,40}$

Non-enzymatic oxidized products from DHA, including 4$\mathrm{F}_{4 \mathrm{t}}$-NeuroP, 10-HDHA, 13-HDHA, and 16-HDHA, were augmented after the walnut diet, even though the diet did not elevate the DHA concentration in the liver. Milne et al. suggested that production of $\mathrm{F}_{4}$-NeuroPs from DHA is dominant compared to $\mathrm{F}_{2}$-IsoPs from $\mathrm{AA}$ in tissues that contain a higher concentration of $\mathrm{DHA}^{41}$ It is plausible that the reduction of $\mathrm{AA}$ as a result of the walnut diet increased the ratio of $\mathrm{DHA} / \mathrm{AA}$ in the liver tissue, which subsequently increased the generation of $4-\mathrm{F}_{4 \mathrm{t}}-\mathrm{NeuroP}$. The elevation of 4$\mathrm{F}_{4 \mathrm{t}}$-NeuroP potentially modulated HDHA in the liver, which was noted by Lee et al., who showed that infusion of $4-\mathrm{F}_{4 \mathrm{t}^{-}}$ NeuroP in rats upregulated HDHA in the liver and brain. ${ }^{42}$ Surprisingly, 4- $\mathrm{F}_{4 \mathrm{t}}-\mathrm{NeuroP}$ and HDHA levels were unaffected by the walnut diet in the heart tissue. The disparity between the liver and heart tissues is unclear. Regardless, it was found by Roy et al. that $4-\mathrm{F}_{4 \mathrm{t}}-\mathrm{NeuroP}$ displayed antiarrhythmic property and protected the heart from ischemia-reperfusion injury. $^{43}$

On the other hand, the walnut diet successfully elevated n-3 PUFAs and reduced n-6 PUFAs in the heart tissue, suggesting that n-3 PUFAs, namely, ALA, EPA, and $\mathrm{DPA}_{\mathrm{n}-3}$, generated in the liver were transported to the heart tissue. Furthermore, 5$\mathrm{F}_{2 \mathrm{t}}$-IsoP but not $15-\mathrm{F}_{2 \mathrm{t}}$-IsoP was significantly reduced by the walnut diet in the liver; the latter is a standard biomarker to assess in vivo oxidative stress status. ${ }^{44}$ Additionally, both $5-\mathrm{F}_{2 \mathrm{t}^{-}}$ IsoP and $15-\mathrm{F}_{2 \mathrm{t}}$-IsoP were not modified by the walnut diet in the heart. To corroborate this observation, the gene expression of antioxidant enzyme catalase was evaluated in the heart tissue and was evidently shown not to be affected by the walnut diet. We further analyzed inflammation-related gene expressions, including IL- $1 \beta$, IL- 6 , and TNF- $\alpha$, in the heart tissue, and as like our findings for HDHA levels, they were not altered. Altogether, the walnut diet did not improve the antioxidant capacity nor anti-inflammation properties in the heart.

The most obvious findings with the walnut diet are the marked elevation of PhytoPs and PhtyoFs in both liver and heart tissues. The total PhytoP amount consumed from the walnut diet by the rats per week was approximately $42 \mathrm{ng}$ on average, while the total amount of the PhytoPs in the liver tissues of the walnut diet group was $122 \mathrm{ng}$ higher than the control group on average (data not shown); this is 3-fold higher than the weekly PhytoP consumption from the diet. It could be postulated that the elevation of PhytoPs in tissues was attributed by not only PhytoPs and PhytoFs in the walnut but also the ALA increment in the walnut diet.

This study suggested that regular consumption of walnut, containing high ALA, increases the n-3/n-6 PUFA ratio in the liver and heart tissues and induces non-enzymatic autoxidation of ALA to release PhytoPs. Furthermore, ALA induced anti- 
inflammatory (HDHA) and reduced pro-inflammatory (HETE) lipid mediators; whether this modification is related to PhytoPs or related to other antioxidant components, such as phytochemicals, of the walnuts requires further elucidation.

\section{ASSOCIATED CONTENT}

\section{SI Supporting Information}

The Supporting Information is available free of charge at https://pubs.acs.org/doi/10.1021/acs.jafc.0c06690.

Composition of control and walnut diets (Table S1), MRM transition measured by LC-MS/MS of PUFAs and their oxidized product standards commercially available (Cayman Chemical, Ann Arbor, MI, U.S.A.) and synthesized by Durand's group (Table S2), primers used for real-time PCR (Table S3), typical LC-MS/MS chromatogram of (A) ALA and (B) 16(RS)-13-epi-ST$\Delta^{14}$-9-phytofuran and sample mass spectra with the structure of (C) ALA and (D) 16(RS)-13-epi-ST- $\Delta^{14}-9$ phytofuran investigated in the study (Figure $\mathrm{S} 1$ ), physical characteristics of rats over 4 weeks of feeding (Figure S2), and gene expressions of IL- $1 \beta$, IL-6, TNF$\alpha$, and catalase measured in the heart tissue (Figure S3) (PDF)

\section{AUTHOR INFORMATION}

\section{Corresponding Author}

Jetty Chung-Yung Lee - School of Biological Sciences, The University of Hong Kong, Pok Fu Lam, Hong Kong Special Administrative Region of the People's Republic of China; () orcid.org/0000-0002-8175-7069; Email: jettylee@ hku.hk; Fax: +852-2559-9114

\section{Authors}

Kin Sum Leung - School of Biological Sciences, The University of Hong Kong, Pok Fu Lam, Hong Kong Special Administrative Region of the People's Republic of China

Jean-Marie Galano - Institut des Biomolécules Max Mousseron, UMR 5247 CNRS, ENSCM, Université de Montpellier, 34093 Montpellier, France

Yu Fung Yau - School of Biological Sciences, The University of Hong Kong, Pok Fu Lam, Hong Kong Special Administrative Region of the People's Republic of China

Camille Oger - Institut des Biomolécules Max Mousseron, UMR 5247 CNRS, ENSCM, Université de Montpellier, 34093 Montpellier, France; 이이. orcid.org/0000-0002-51775792

Thierry Durand - Institut des Biomolécules Max Mousseron, UMR 5247 CNRS, ENSCM, Université de Montpellier, 34093 Montpellier, France

\section{Notes}

The authors declare no competing financial interest.

\section{REFERENCES}

(1) Sabate, J.; Oda, K.; Ros, E. Nut consumption and blood lipid levels: A pooled analysis of 25 intervention trials. Arch. Intern. Med. 2010, 170 (9), 821-7.

(2) Kendall, C. W.; Josse, A. R.; Esfahani, A.; Jenkins, D. J. Nuts, metabolic syndrome and diabetes. Br. J. Nutr. 2010, 104 (4), 465-73.

(3) Luo, C.; Zhang, Y.; Ding, Y.; Shan, Z.; Chen, S.; Yu, M.; Hu, F. B.; Liu, L. Nut consumption and risk of type 2 diabetes, cardiovascular disease, and all-cause mortality: A systematic review and meta-analysis. Am. J. Clin. Nutr. 2014, 100 (1), 256-69.

(4) Ros, E. Health benefits of nut consumption. Nutrients 2010, 2 (7), 652-82.

(5) Vinson, J. A.; Cai, Y. Nuts, especially walnuts, have both antioxidant quantity and efficacy and exhibit significant potential health benefits. Food Funct. 2012, 3 (2), 134-40.

(6) Maguire, L. S.; O’Sullivan, S. M.; Galvin, K.; O’Connor, T. P.; O'Brien, N. M. Fatty acid profile, tocopherol, squalene and phytosterol content of walnuts, almonds, peanuts, hazelnuts and the macadamia nut. Int. J. Food Sci. Nutr. 2004, 55 (3), 171-8.

(7) Barrera, F.; George, J. The role of diet and nutritional intervention for the management of patients with NAFLD. Clin Liver Dis 2014, 18 (1), 91-112.

(8) Han, J. M.; Jo, A. N.; Lee, S. M.; Bae, H. S.; Jun, D. W.; Cho, Y. K.; Suk, K. T.; Yoon, J. H.; Ahn, S. B.; Cho, Y. J.; Kim, S. W.; Jang, E. C. Associations between intakes of individual nutrients or whole food groups and non-alcoholic fatty liver disease among Korean adults. J. Gastroenterol. Hepatol. 2014, 29 (6), 1265-72.

(9) Manninen, V.; Elo, M. O.; Frick, M. H.; Haapa, K.; Heinonen, O. P.; Heinsalmi, P.; Helo, P.; Huttunen, J. K.; Kaitaniemi, P.; Koskinen, P.; et al. Lipid alterations and decline in the incidence of coronary heart disease in the Helsinki Heart Study. JAMA, J. Am. Med. Assoc. 1988, 260 (5), 641-651.

(10) Feldman, E. B. The scientific evidence for a beneficial health relationship between walnuts and coronary heart disease. J. Nutr. 2002, 132 (5), 1062S-1101S

(11) Davis, P.; Valacchi, G.; Pagnin, E.; Shao, Q.; Gross, H. B.; Calo, L.; Yokoyama, W. Walnuts reduce aortic ET-1 mRNA levels in hamsters fed a high-fat, atherogenic diet. J. Nutr. 2006, 136 (2), 42832.

(12) Medina, S.; Collado-Gonzalez, J.; Ferreres, F.; LondonoLondono, J.; Jimenez-Cartagena, C.; Guy, A.; Durand, T.; Galano, J. M.; Gil-Izquierdo, A. Quantification of phytoprostanes - bioactive oxylipins - and phenolic compounds of Passiflora edulis Sims shell using UHPLC-QqQ-MS/MS and LC-IT-DAD-MS/MS. Food Chem. 2017, 229, 1-8.

(13) Yonny, M. E.; Rodriguez Torresi, A.; Cuyamendous, C.; Reversat, G.; Oger, C.; Galano, J. M.; Durand, T.; Vigor, C.; Nazareno, M. A. Thermal Stress in Melon Plants: Phytoprostanes and Phytofurans as Oxidative Stress Biomarkers and the Effect of Antioxidant Supplementation. J. Agric. Food Chem. 2016, 64 (44), 8296-8304.

(14) Carrasco-Del Amor, A. M.; Aguayo, E.; Collado-Gonzalez, J.; Guy, A.; Galano, J. M.; Durand, T.; Gil-Izquierdo, A. Impact of processing conditions on the phytoprostanes profile of three types of nut kernels. Free Radical Res. 2017, 51 (2), 141-147.

(15) Collado-Gonzalez, J.; Medina, S.; Durand, T.; Guy, A.; Galano, J. M.; Torrecillas, A.; Ferreres, F.; Gil-Izquierdo, A. New UHPLCQqQ-MS/MS method for quantitative and qualitative determination of free phytoprostanes in foodstuffs of commercial olive and sunflower oils. Food Chem. 2015, 178, 212-20.

(16) Minghetti, L.; Salvi, R.; Lavinia Salvatori, M.; Ajmone-Cat, M. A.; De Nuccio, C.; Visentin, S.; Bultel-Ponce, V.; Oger, C.; Guy, A.; Galano, J. M.; Greco, A.; Bernardo, A.; Durand, T. Nonenzymatic oxygenated metabolites of $\alpha$-linolenic acid B1- and L1-phytoprostanes protect immature neurons from oxidant injury and promote differentiation of oligodendrocyte progenitors through PPAR- $\gamma$ activation. Free Radical Biol. Med. 2014, 73, 41-50.

(17) González Roldán, N.; Engel, R.; Dupow, S.; Jakob, K.; Koops, F.; Orinska, Z.; Vigor, C.; Oger, C.; Galano, J.-M.; Durand, T.; Jappe, U.; Duda, K. A. Lipid Mediators From Timothy Grass Pollen Contribute to the Effector Phase of Allergy and Prime Dendritic Cells for Glycolipid Presentation. Front. Immunol. 2019, 10, 974.

(18) Cuyamendous, C.; Leung, K. S.; Durand, T.; Lee, J. C.; Oger, C.; Galano, J. M. Synthesis and discovery of phytofurans: Metabolites of $\alpha$-linolenic acid peroxidation. Chem. Commun. (Cambridge, U. K.) 2015, 51 (86), 15696-9. 
(19) Cuyamendous, C.; de la Torre, A.; Lee, Y. Y.; Leung, K. S.; Guy, A.; Bultel-Ponce, V.; Galano, J. M.; Lee, J. C.; Oger, C.; Durand, $\mathrm{T}$. The novelty of phytofurans, isofurans, dihomo-isofurans and neurofurans: Discovery, synthesis and potential application. Biochimie 2016, 130, 49-62.

(20) Folch, J.; Lees, M.; Sloane Stanley, G. H. A simple method for the isolation and purification of total lipides from animal tissues. $J$. Biol. Chem. 1957, 226 (1), 497-509.

(21) Leung, K.; Galano, J.-M.; Durand, T.; Lee, J. Profiling of Omega-Polyunsaturated Fatty Acids and Their Oxidized Products in Salmon after Different Cooking Methods. Antioxidants 2018, 7 (8), 96.

(22) Dupuy, A.; Le Faouder, P.; Vigor, C.; Oger, C.; Galano, J. M.; Dray, C.; Lee, J. C.; Valet, P.; Gladine, C.; Durand, T.; BertrandMichel, J. Simultaneous quantitative profiling of 20 isoprostanoids from omega- 3 and omega- 6 polyunsaturated fatty acids by LC-MS/ MS in various biological samples. Anal. Chim. Acta 2016, 921, 46-58.

(23) Lee, Y. Y.; Wong, C. K.; Oger, C.; Durand, T.; Galano, J. M.; Lee, J. C. Prenatal exposure to the contaminant perfluorooctane sulfonate elevates lipid peroxidation during mouse fetal development but not in the pregnant dam. Free Radical Res. 2015, 49 (8), 1015-25.

(24) Rajaram, S. Health benefits of plant-derived $\alpha$-linolenic acid. Am. J. Clin. Nutr. 2014, 100 (suppl_1), 443S-448S.

(25) Tapiero, H.; Ba, G. N.; Couvreur, P.; Tew, K. D. Polyunsaturated fatty acids (PUFA) and eicosanoids in human health and pathologies. Biomed. Pharmacother. 2002, 56 (5), 215-222.

(26) Calder, P. C. n-3 polyunsaturated fatty acids, inflammation, and inflammatory diseases. Am. J. Clin. Nutr. 2006, 83 (6), 1505S-1519S.

(27) Thomas, J.; Thomas, C. J.; Radcliffe, J.; Itsiopoulos, C. Omega3 Fatty Acids in Early Prevention of Inflammatory Neurodegenerative Disease: A Focus on Alzheimer's Disease. BioMed. Res. Int. 2015, 2015, 172801.

(28) Burdge, G. C.; Calder, P. C. Conversion of $\alpha$-linolenic acid to longer-chain polyunsaturated fatty acids in human adults. Reprod., Nutr., Dev. 2005, 45 (5), 581-97.

(29) Jahn, U.; Galano, J. M.; Durand, T. A cautionary note on the correct structure assignment of phytoprostanes and the emergence of a new prostane ring system. Prostaglandins, Leukotrienes Essent. Fatty Acids 2010, 82 (2-3), 83-6.

(30) Blank, C.; Neumann, M. A.; Makrides, M.; Gibson, R. A. Optimizing DHA levels in piglets by lowering the linoleic acid to $\alpha$ linolenic acid ratio. J. Lipid Res. 2002, 43 (9), 1537-43.

(31) Tu, W. C.; Cook-Johnson, R. J.; James, M. J.; Muhlhausler, B. S.; Gibson, R. A. Omega-3 long chain fatty acid synthesis is regulated more by substrate levels than gene expression. Prostaglandins, Leukotrienes Essent. Fatty Acids 2010, 83 (2), 61-8.

(32) Gibson, R. A.; Neumann, M. A.; Lien, E. L.; Boyd, K. A.; Tu, W. C. Docosahexaenoic acid synthesis from $\alpha$-linolenic acid is inhibited by diets high in polyunsaturated fatty acids. Prostaglandins, Leukotrienes Essent. Fatty Acids 2013, 88 (1), 139-46.

(33) Voss, A.; Reinhart, M.; Sankarappa, S.; Sprecher, H. The metabolism of $7,10,13,16,19$-docosapentaenoic acid to $4,7,10,13,16,19$-docosahexaenoic acid in rat liver is independent of a 4-desaturase. J. Biol. Chem. 1991, 266 (30), 19995-20000.

(34) Jump, D. B.; Depner, C. M.; Tripathy, S. Omega-3 fatty acid supplementation and cardiovascular disease. J. Lipid Res. 2012, 53 (12), 2525-45.

(35) Endo, J.; Arita, M. Cardioprotective mechanism of omega-3 polyunsaturated fatty acids. J. Cardiol 2016, 67 (1), 22-7.

(36) Takamura, M.; Kurokawa, K.; Ootsuji, H.; Inoue, O.; Okada, H.; Nomura, A.; Kaneko, S.; Usui, S. Long-Term Administration of Eicosapentaenoic Acid Improves Post-Myocardial Infarction Cardiac Remodeling in Mice by Regulating Macrophage Polarization. J. Am. Heart Assoc. 2017, 6 (2), e004560.

(37) Lockette, W. E.; Webb, R. C.; Culp, B. R.; Pitt, B. Vascular reactivity and high dietary eicosapentaenoic acid. Prostaglandins 1982, 24 (5), 631-9.
(38) Terano, T.; Salmon, J. A.; Moncada, S. Biosynthesis and biological activity of leukotriene B5. Prostaglandins 1984, 27 (2), 217-32.

(39) Carvalho, M.; Ferreira, P. J.; Mendes, V. S.; Silva, R.; Pereira, J. A.; Jeronimo, C.; Silva, B. M. Human cancer cell antiproliferative and antioxidant activities of Juglans regia L. Food Chem. Toxicol. 2010, 48 (1), 441-7.

(40) Bolling, B. W.; Chen, C. Y.; McKay, D. L.; Blumberg, J. B. Tree nut phytochemicals: Composition, antioxidant capacity, bioactivity, impact factors. A systematic review of almonds, Brazils, cashews, hazelnuts, macadamias, pecans, pine nuts, pistachios and walnuts. Nutr. Res. Rev. 2011, 24 (2), 244-75.

(41) Milne, G. L.; Morrow, J. D.; Picklo, M. J., Sr. , Elevated oxidation of docosahexaenoic acid, 22:6 (n-3), in brain regions of rats undergoing ethanol withdrawal. Neurosci. Lett. 2006, 405 (3), 172174.

(42) Lee, Y. Y.; Galano, J. M.; Leung, H. H.; Balas, L.; Oger, C.; Durand, T.; Lee, J. C. Nonenzymatic oxygenated metabolite of docosahexaenoic acid, 4(RS)-4-F4t -neuroprostane, acts as a bioactive lipid molecule in neuronal cells. FEBS Lett. 2020, 594 (11), 17971808.

(43) Roy, J.; Oger, C.; Thireau, J.; Roussel, J.; Mercier-Touzet, O.; Faure, D.; Pinot, E.; Farah, C.; Taber, D. F.; Cristol, J. P.; Lee, J. C.; Lacampagne, A.; Galano, J. M.; Durand, T.; Le Guennec, J. Y. Nonenzymatic lipid mediators, neuroprostanes, exert the antiarrhythmic properties of docosahexaenoic acid. Free Radical Biol. Med. 2015, 86, 269-78.

(44) Morrow, J. D.; Roberts, L. J. The isoprostanes: Unique bioactive products of lipid peroxidation. Prog. Lipid Res. 1997, 36 (1), $1-21$. 